\title{
Romboencefalitis: una forma de infección por Listeria monocytogenes en el sistema nervioso central
}

\author{
Sergio Illanes $D^{1}$, Pablo Araya $C^{2}$, Sergio Ferrer $D^{1}$, \\ Luis Cartier $\mathbf{R}^{2}$, Mauricio Bravo $\mathbf{M}^{1}$, Sergio Castillo $C^{2}$. \\ Rhomboencephalitis caused by \\ listeria monocytogenes infection. \\ Report of three cases
}

Listeria monocytogenes infections can involve the central nervous system in the form of a rhomboencephalitis. Three possible cases of rhomboencephalitis by Listeria monocytogenes are reported ( 2 females, aged 44 and 49 and a man of 36 years old). The three cases were preceded by an unspecific prodrome of headache, vertigo and fever in absence of a meningeal syndrome. The neurological stage was defined by the unilateral involvement of cranial nerves and the cerebellum and a clear inflammatory cerebrospinal fluid (CSF) with the presence of polymorphonuclear leukocytes, and normal glucose and protein levels. A magnetic nuclear resonance (MRI) showed the appearance of characteristic images, present in the bulboprotuberancial region. These images are one of the most constant features of this disease, reported in the literature. The early diagnosis of rhomboencephalitis was based on the clinical picture, the study of the CSF and the MRI, allowing the use of antimicrobials, prior to microbiological identification. Therefore, the risk of brain stem and cardiac complications of the disease is reduced (Rev Méd Chile 2003; 131: 921-8).

(Key Words: Encephalitis; Listeria monocytogenes Rhomboencephalon)

Recibido el 14 de enero, 2003. Aceptado en versión corregida el 12 de junio, 2003.

${ }^{1}$ Servicio de Neurología Hospital Militar, Santiago, Chile. ${ }^{2}$ Servicio de Neurología Hospital del Salvador, Santiago, Chile.

L a Listeria monocytogenes es un cocobacilo grampositivo, anaerobio facultativo que penetra en el organismo por el tubo digestivo. Puede

Correspondencia a: Dr. Sergio Illanes D. Holanda 050, $3^{\text {er }}$ piso, Servicio de Neurología, Hospital Militar de Santiago. Santiago de Chile. Teléfonos: 2436761, 3653341, 092990149. Fax: 3653147 (Hospital Militar). E mail: donchecho@yahoo.com - sergio_illanes@hotmail.com ser aislada desde la tierra, polvo, abono, agua estancada, agua cristalina, plantas e incluso de los alimentos procesados y almacenados a bajas temperaturas. Gran cantidad de los alimentos que consumimos pueden estar contaminados con Listeria monocytogenes. La tasa de aislamiento del germen en vegetales sin lavar, leche no pasteurizada, pescado y carne, incluyendo pollo y la carne dispuesta para la venta en supermercados oscila entre $15 \%$ y $70 \%{ }^{1}$. 
Sin embaryo, la listeriosis es rara. En Europa se ha visto una incidencia anual de 0,2/100.000 habitantes. La infección por Listeria monocytogenes suele afectar a ancianos y a niños, excepcionalmente a adultos sanos ${ }^{2}$. Habitualmente esta bacteria compromete el sistema nervioso central (SNC) manifestándose como una meningitis agu$\mathrm{da}^{3}$, aunque puede expresarse como una meningitis crónica que se asocia a abscesos cerebrales 0 medulares. El particular compromiso del tronco cerebral y cerebelo aparece como excepcional. Este compromiso romboencefálico lleva aparejado depresión respiratoria o paro cardiorrespiratorio ${ }^{4}$.

La revisión de la literatura a nivel mundial, entre 1964 y 1997, recopiló 820 pacientes con listeriosis cerebral. El 24\% se asociaba a neoplasias, de predominio hematológico; $21 \%$ a trasplantes, principalmente de riñón y $36 \%$ a pacientes no inmunocomprometidos ${ }^{5}$. La presentación fue la de una meningitis-meningoencefalitis en $97 \%$ que se complicó con un absceso-cerebritis en 32\%. La mortalidad fue $27 \%$ y $50 \%$, respectivamente ${ }^{5}$. La literatura europea y más recientemente la norteamericana ha consignado algunos casos de romboencefalitis por Listeria, los cuales han evidenciado una forma característica de presentación clínica que permite identificar este proceso de otras infecciones del SNC ${ }^{6-8}$. El concepto de romboencefalitis alude a la exclusiva localización de este proceso inflamatorio en la región de la protuberancia y del bulbo raquídeo.

\section{Caso Cúnico 1}

Mujer de 44 años, sin antecedentes mórbidos de importancia, que 6 días antes de su ingreso había iniciado un cuadro de vértigo objetivo, náuseas, vómitos, cefalea y alteración de la marcha. Se hospitalizó en el Servicio de Neurología del Hospital Militar el día 12-03-97.

Examen físico: Estaba febril, con deshidratación leve y hemodinámicamente estable. Se apreciaba somnolienta, orientada en tiempo y espacio, con capacidad para invertir series automáticas. Pupilas isocóricas, reflejos fotomotor y consensual presentes, nistagmus multidireccional, hiperestesia del trigémino sensitivo izquierdo y disminución del reflejo corneano. Paresia del velo del paladar bilateral mayor a izquierda. Paresia facial central derecha. Disfagia y rinolalia marcada con desviación lingual a la izquierda. Dismetría e hipotonía del hemicuerpo izquierdo, hipoalgesia e hipoestesia táctil y astereognosia izquierda. Reflejo plantar flexor bilateral.

Estudio: El líquido cefalorraquídeo (LCR) tuvo un aspecto levemente opalescente, proteínas y glucosa dentro de límites normales. 820 células $/ \mathrm{mm}^{3}$ con $98 \%$ de polimorfonucleares (PMN). Los cultivos de LCR confirmaron al octavo día la presencia de una Listeria monocytogenes. Los hemocultivos fueron positivos para Listeria monocytogenes en 3 oportunidades. Resonancia nuclear magnética (RNM) de encéfalo (11-03-97): se observa una zona de hiperintensidad que compromete la mitad izquierda del segmento cervical superior, región retroolivar izquierda del bulbo raquídeo, mitad de la protuberancia con extensión al pedúnculo cerebeloso superior y medio izquierdo. La lesión protuberancial abarca la mitad lateral izquierda y se extiende hasta la pared del $4^{\circ}$ ventrículo. Todos estos cambios se observan con mayor intensidad en la secuencia de densidad protónica T2, en secuencia T1 la lesión es menos notable y se aprecia ligera hipointensidad. El resto del encéfalo es normal (Figura 1).

Evolución. Como el cuadro clínico evocaba una romboencefalitis y se formuló la hipótesis de una listeriosis se inició en forma inmediata tratamiento antibiótico con ampicilina $2 \mathrm{~g}$ cada $4 \mathrm{~h}$ iv, asociado a gentamicina $80 \mathrm{mg}$ cada $12 \mathrm{~h}$ iv. La enferma al cuarto día se encontraba mejor, consciente, lúcida, afebril, disártrica, persistía el nistagmus multidireccional aunque de menor amplitud que al inicio. Se comprobó cefaloparesia. Al décimo día se encontraba mejor, más activa y había disminuido la cefaloparesia. El nistagmus persistió en forma horizontal. En el LCR de control la celularidad disminuyó a 51 elementos $/ \mathrm{mm}^{3}$, con predominio mononuclear e hipoproteinorraquia. Al décimo sexto día mantenía el nistagmus horizontal a derecha y anestesia del $\mathrm{V}$ par izquierdo, menor hipotonía y dismetría izquierda. Se sentaba con rapidez y mantenía el equilibrio. La sensibilidad táctil, térmica-dolorosa y propioceptiva eran normales. Apareció dolor trigeminal que se expresó por descargas eléctricas espontáneas en la segunda rama izquierda. 


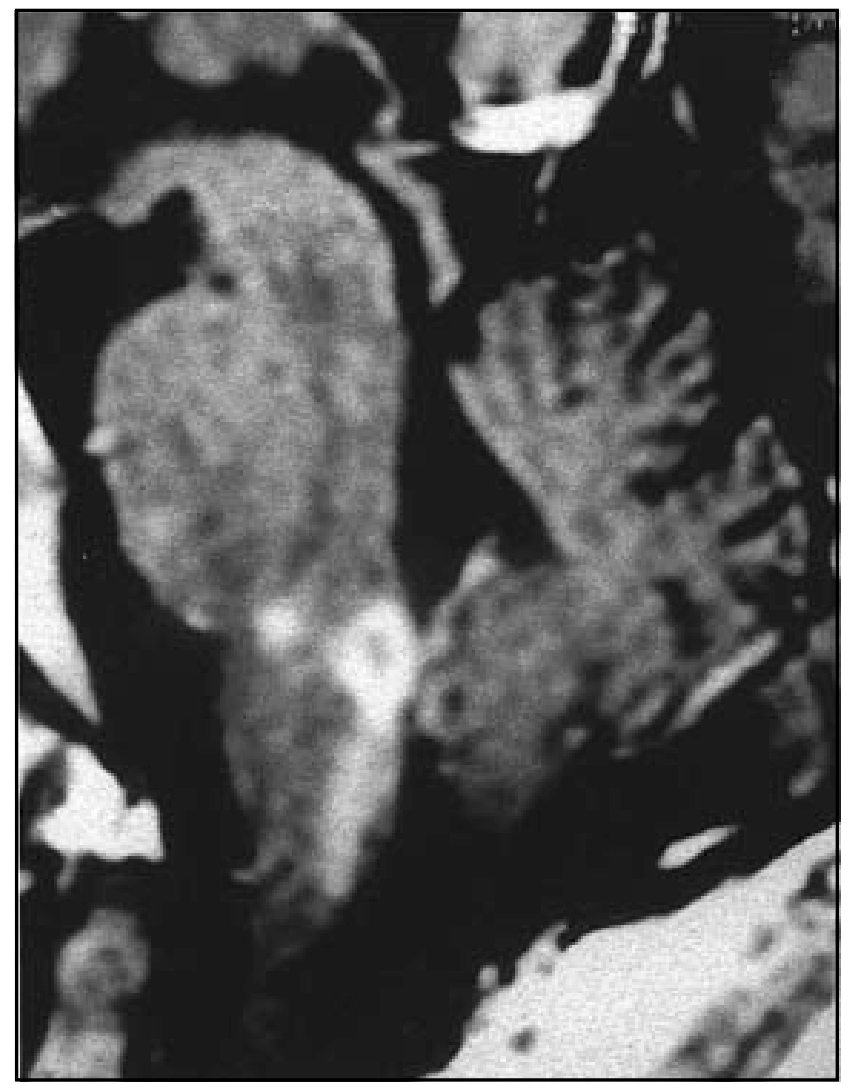

Figura 1.

Transcurridos 22 días la paciente recuperó la sensibilidad de la región preauricular. La punción lumbar de control demostró LCR de aspecto incoloro, con 5 células $/ \mathrm{mm}^{3}$, glucosa y proteínas normales. El estudio inmunológico fue normal. La serología para el virus de inmunodeficiencia humana (VIH) fue negativa y el VDRL (Venereal Disease Research Laboratory) resultó no reactivo. Fue dada de alta al completar 20 días de tratamiento antibiótico parenteral. Examinada el día 2-07-97 se comprobó leve dismetría de la extremidad superior derecha y ligera ataxia de la marcha, sin necesitar apoyo para deambular. El dolor trigeminal con características de causalgia se habían acentuado en la mejilla y región nasolabial izquierda. Se realizó una RNM de cerebro el 14-05-97 que demostró en secuencia T2 señal de hiperintensidad retroolivar izquierda y pedúnculos cerebelosos superior y medio izquierdos. En T1 no se observaron lesiones.
Con inyección de gadolinio se obtuvo leve reforzamiento. En resumen, franca regresión de la lesión.

\section{Caso Cú́nico 2}

Mujer de 49 años, sin antecedentes mórbidos de importancia que consultó por cuadro de 4 días de evolución caracterizado por congestión nasal, fiebre $\left(38,5^{\circ} \mathrm{C}\right.$ axilar), cefalea holocranea progresiva asociada a vértigo objetivo, náuseas $\mathrm{y}$ parestesias en región facial derecha. Fue evaluada por otorrinolaringología solicitándose radiografía de senos paranasales que reveló velamiento de celdas etmoidales bilaterales y seno maxilar derecho, radiografía $(\mathrm{Rx})$ de tórax y tomografía axial computada (TAC) de encéfalo sin hallazgos patológicos. Se diagnosticó una rinosinusitis iniciándose antibioterapia con amoxicilina-ácido clavulánico. Debido a la persistencia del cuadro de cefalea y vértigo fue evaluada en el Servicio de Neurología del Hospital Militar de Santiago, decidiéndose su hospitalización el 30-05-02.

Examen físico. La enferma se mostró atenta, lúcida, muy angustiada, afebril y hemodinámicamente estable. Pupilas isocóricas y reactivas, fondo de ojo normal, nistagmus horizontal a derecha. Tono y fuerza muscular conservada, con leve disimetría de brazo derecho. Examen sensitivo normal. Marcha atáxica con tendencia a caer hacia la derecha. La prueba de Romberg negativa. La paciente presentó un deterioro gradual de su estado general. El examen neurológico mostró la aparición de paresia e hipoestesia facial izquierda, paresia del hemivelo palatino derecho y paresia del esternocleidomastoideo izquierdo. Se agregó disfagia y disfonía por parálisis de cuerda vocal derecha. Se observó mayor alteración de la marcha y Romberg positivo con caída a la derecha.

Estudio. LCR de aspecto levemente opalescente, 570 células $/ \mathrm{mm}^{3}$ con predominio mononuclear de 86\%. Proteínas y glucosa dentro de límites normales. El cultivo fue negativo. La RNM (06-06-02) fue compatible con un proceso granulomatoso 
cisternal y compromiso de la región ponto-bulbar y núcleo del nervio trigémino derecho (Figura 2). Con el hallazgo descrito se decidió iniciar tratamiento antibiótico con ampicilina $2 \mathrm{~g} \mathrm{c} / 4 \mathrm{~h}$ iv, agregándose Gentamicina $80 \mathrm{mg}$ c/ 8 iv, 3 días más tarde. Se repitió el estudio de $\mathrm{LCR}$, al $3^{\text {er }}$ y $6^{0}$ día de antibioterapia poniendo en evidencia disminución de celularidad a $340 / \mathrm{mm}^{3}$ y $40 / \mathrm{mm}^{3}$ respectivamente, de predominio mononuclear. Los hemocultivos seriados resultaron negativos, anticuerpos anti VIH-1 y VIH-2: negativos, Elisa para Cisticercosis (Inmunoglobulina-G): negativo, proteína $\mathrm{C}$ reactiva (PCR) para tuberculosis (TBC) en LCR y cultivo TBC en LCR: negativo.

Evolución. Al décimo día de antibioterapia se apreció mejoría de su estado general, disminución del vértigo y mayor estabilidad de la marcha. Persistió la disfonía y la disfagia, nistagmus horizontal leve, hipotonía braquio-crural derecha y compromiso sensitivo en territorio trigeminal derecho. Cumplidos 15 días de antibioterapia, se apreció franca disminución de la dismetría de extremidades derechas, menor disfagia y marcha más estable. Persistía dolor neurálgico en territorio trigeminal derecho. Se solicitó RNM de control (1406-02) que mostró la lesión bulbopontina derecha sin cambios. Luego de 28 días de antibióticos y 39 días de hospitalización se decidió el alta, persistiendo algia facial en hemicara derecha, disfagia, disfonía leve y con marcha levemente atáxica. Se realizó una RNM (12-12-02) de control en la cual se demostró franca regresión de la lesión granulomatosa bulbopontina, con disminución importante de su extensión (Figura 3).

\section{Caso CLínico 3}

Paciente de 36 años de sexo masculino, con el antecedente de ingesta excesiva de alcohol y consumo de drogas. Inició su enfermedad con un cuadro caracterizado por compromiso de estado general, sensación febril y cefalea. Al cuarto día aparecieron náuseas y vómitos asociados a sensación vertiginosa y diplopía. Seguidamente se agregó disfagia e intensa inestabilidad de la marcha que le hicieron consultar en el Servicio de Urgencia.

Figura 2.

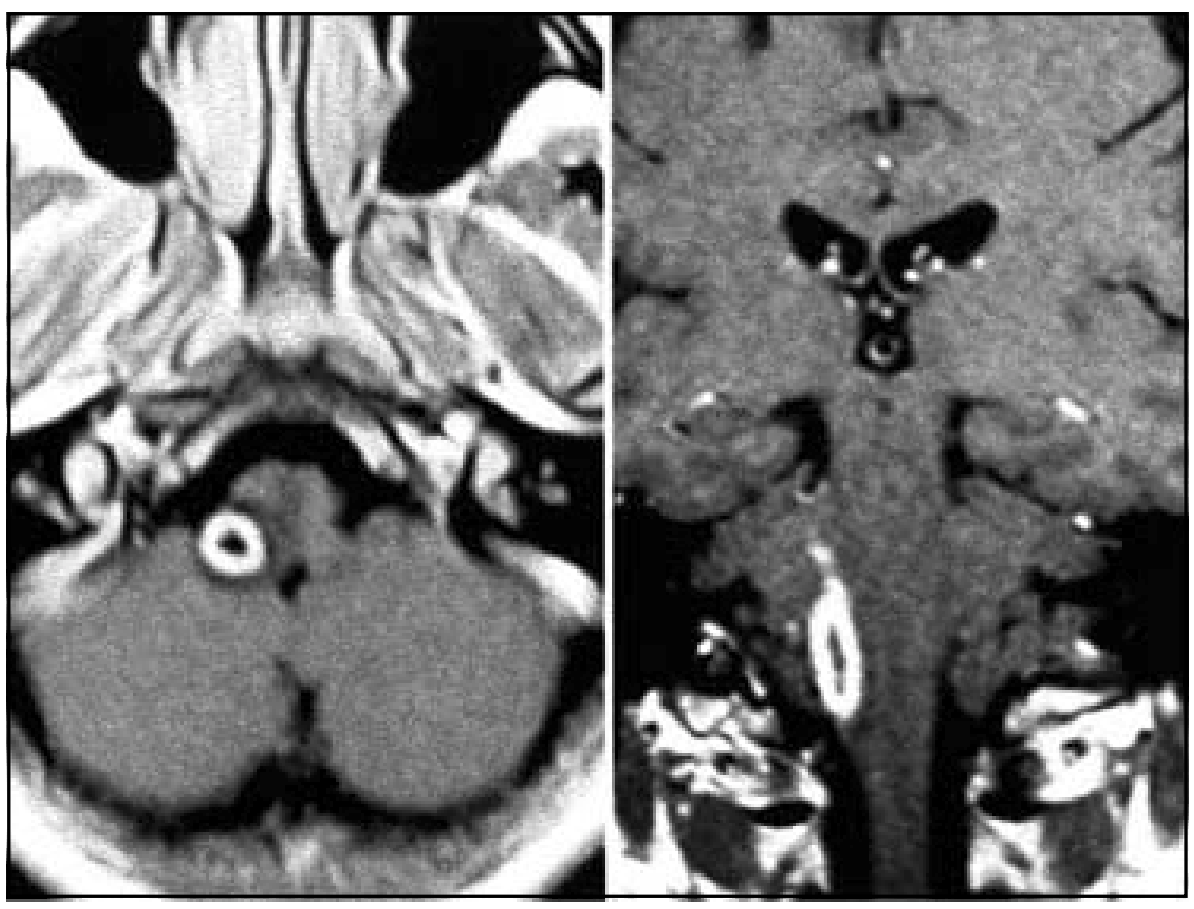




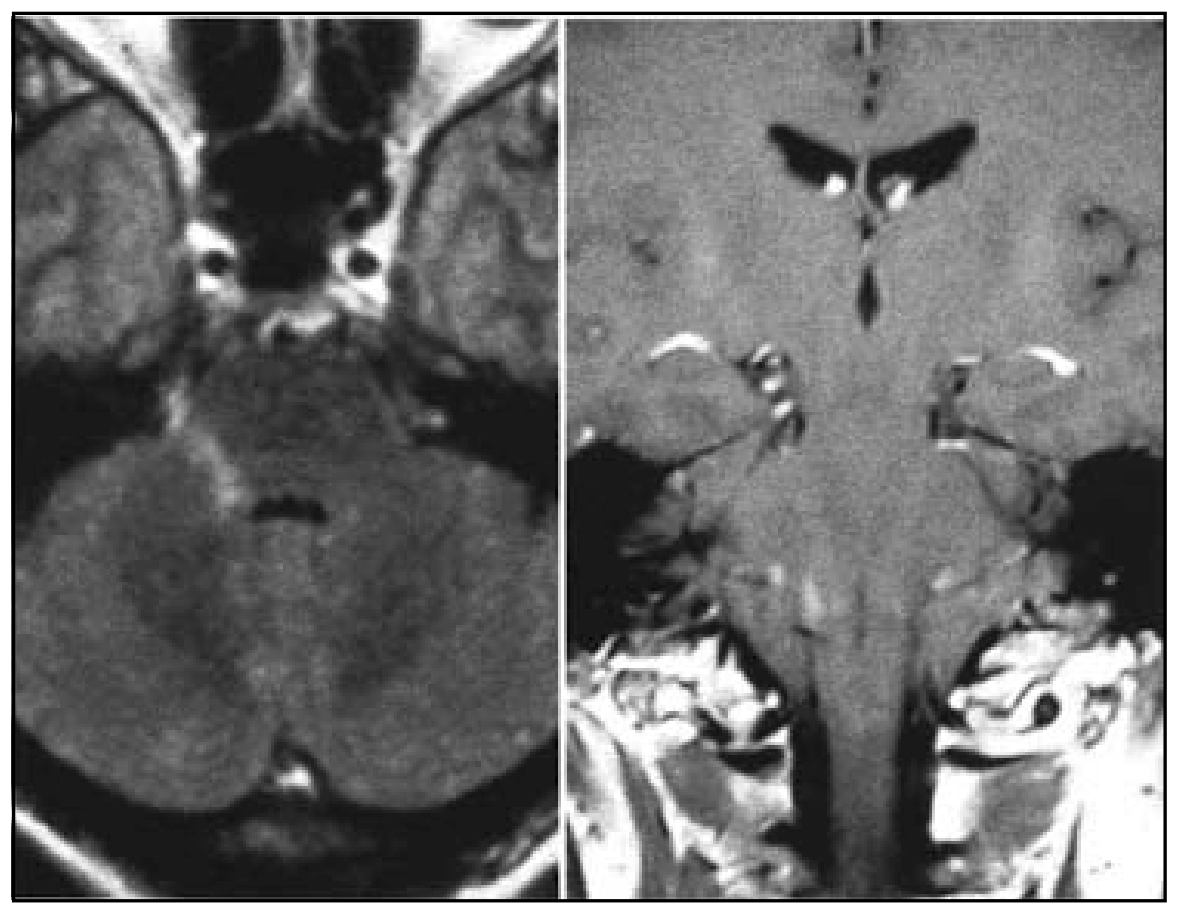

Figura 3.

Examen físico. Destacaba fiebre de $39^{\circ} \mathrm{C}$, ausencia de compromiso de conciencia, paresia de recto externo ocular izquierdo, paresia facial periférica izquierda, paresia de hemivelo palatino izquierdo y desviación de la lengua hacia izquierda al protruirla. También se encontró dismetría en extremidad superior izquierda y leve rigidez de nuca.

Estudio. El estudio de hemocultivos no mostró desarrollo bacteriano. El LCR fue claro, destacándose una pleocitosis de 145 células con $85 \%$ de polimorfonucleares, proteínas $0,65 \mathrm{gr} \%$ y glucosa normal. Un segundo estudio de LCR $48 \mathrm{~h}$ más tarde mostró líquido claro con una pleocitosis de 1.000 células con $90 \%$ de polimorfonucleares, discreta elevación de las proteínas a $0,70 \mathrm{~g} / \mathrm{dL}$ y glucosa normal. El estudio con Gram directo, cultivo corriente, tinta china, cultivo de hongos, baciloscopia, cultivo de Koch, PCR para TBC, virus Herpes y varicela Zoster en el LCR resultaron negativos. La TAC de encéfalo fue normal.
Evolución. La juventud del paciente y el daño focal del romboencéfalo hizo plantear una romboencefalitis por Listeria, iniciándose tratamiento con ampicilina y gentamicina. A las $72 \mathrm{~h}$ después de su ingreso, el paciente desarrolló un rápido compromiso cualitativo de conciencia con intranquilidad. Doce horas más tarde se agregó un cuadro de hipoventilación progresivo que hizo necesario su traslado a la unidad de tratamiento intensivo. Luego apareció bradicardia llegando al paro cardiorrespiratorio que se recuperó a los 8 min. A continuación inició status epilepticus de difícil manejo terapéutico logrando su control con dosis altas de tiopental, fenitoína, valproato y midazolam. Permaneció con actividad epiléptica continua al electroencefalograma durante una semana. No recuperó la conciencia y derivó hacia un estado vegetativo.

El estudio con RNM fue posible 10 días después de su ingreso, en el cual se visualizaron lesiones de protuberancia baja, cerebelo y bulbo raquídeo del lado izquierdo. Además, alteraciones de los ganglios basales, compatibles con encefalopatía hipóxico isquémica (Figura 4). 


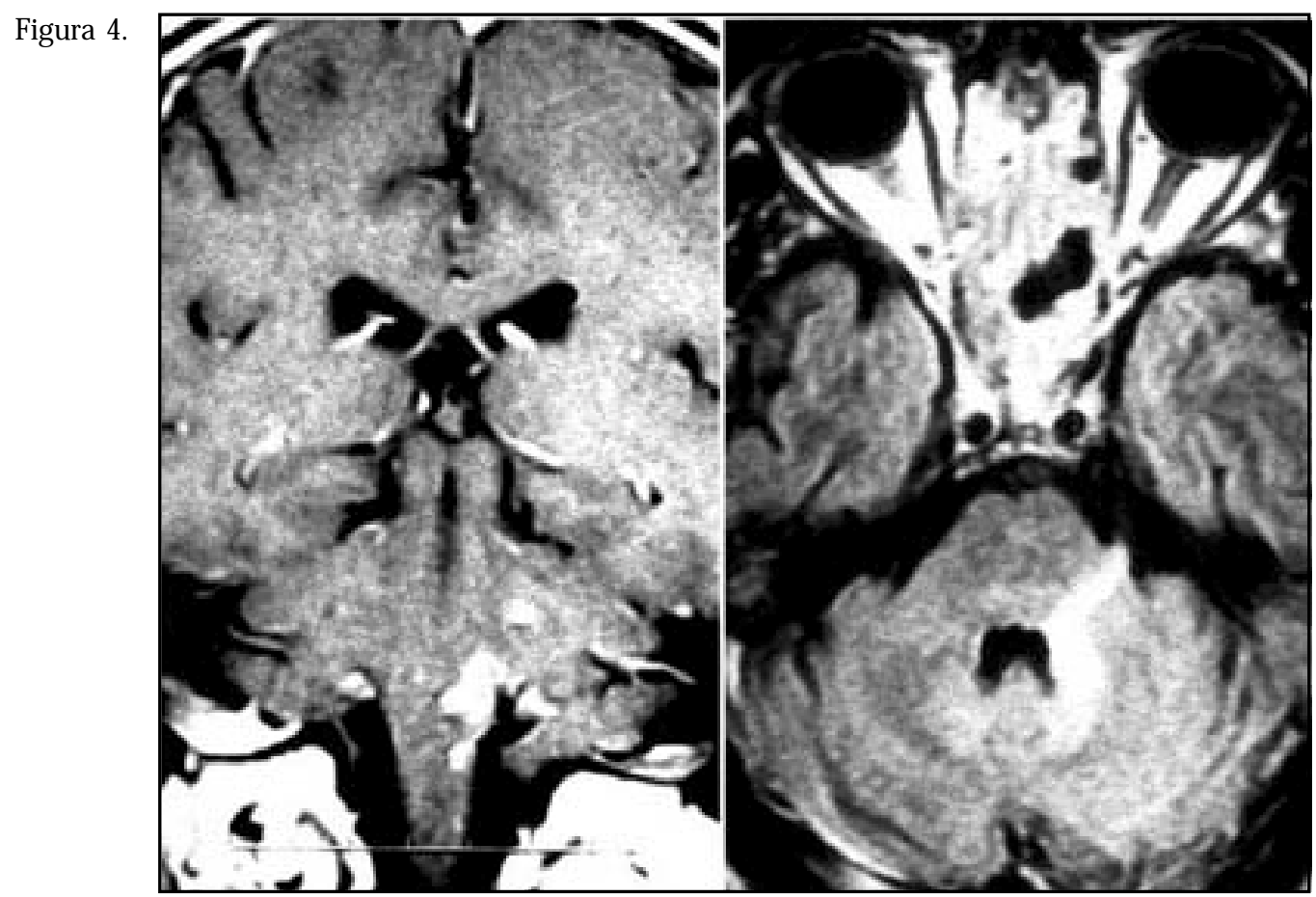

Se suspendieron los antibióticos a las tres semanas obteniéndose un nuevo LCR que fue normal. El paciente falleció al cabo de 2 meses.

\section{DiscUSIÓN}

El término romboencefalitis es un denominador común para una entidad descrita por Bickerstaff en 1950, que expresa un cuadro inflamatorio del romboencéfalo de etiología no precisada que se presenta en niños y adolescentes y se muestra como una enfermedad muy grave, pero que en general tiene un pronóstico benigno ${ }^{9}$. A este síndrome se le supone una patogenia inmunológica-viral. En cambio, la romboencefalitis por Listeria monocytogenes ocurre solamente en adultos y tiene un pronóstico grave e incluso fatal. El primer caso de romboencefalitis por Listeria fue publicado por Eks, en Alemania en 1957, y hasta el año 1964 no se había consignado ningún caso en la literatura inglesa ${ }^{10}$. En 1993, Amstrong y Fung revisaron lo publicado hasta entonces logrando analizar las manifestaciones clínicas de $63 \operatorname{casos}^{10}$. Desde su análisis los autores creyeron fundamental establecer criterios que permitieron definir esta entidad; consideraron que son necesarios tres elementos: a) evidencias clínico-patológicas de una infección aguda del tronco cerebral, b) ausencia clínico-radiológica 0 patológica de lesión de la corteza cerebral, y c) la demostración de la presencia de Listeria monocytogenes en sangre, LCR o tejido cerebral. Los casos que no cumplen con la última premisa debieron ser considerados sólo como probables.

Esta serie de pacientes ha puesto de manifiesto elementos clínicos como el significado del período prodrómico, los hallazgos de la RNM y LCR que nos parecen elementos significativos en el diagnóstico de la enfermedad. Es necesario destacar la sintomatología inicial que se desarrolló larvadamente 4 a 6 días antes de la instalación del cuadro neurológico bien definido. Los pródromos consistieron en vértigo, cefalea, fiebre y leve compromiso del sensorio. Ninguno presentó un síndrome meníngeo significativo. Estos hechos 
retardaron el diagnóstico hasta la aparición de los síntomas focales neurológicos.

En cada uno de ellos se formuló el diagnóstico de romboencefalitis, fundamentado en el compromiso nuclear múltiple de pares craneanos bulboprotuberanciales que se asociaron a un síndrome cerebeloso. En la revisión de Amstrong y Fung, la parálisis de los pares craneanos igual que en nuestros casos se asocia a signos cerebelosos 0 compromiso de tractos sensitivo-motores en 46\%; quedando $44 \%$ que sólo presenta compromiso aislado de pares craneanos. El síndrome también se ha descrito con un compromiso cerebeloso o de tractos sensitivo-motores sin afección de pares craneanos en 10\%. Es frecuente que el daño del tronco cerebral exprese falla del centro respiratorio, que puede conducir a un paro cardiorrespiratorio.

El estudio con RNM es el examen ideal en los síndromes del tronco cerebral, puesto que la TAC puede no mostrar las lesiones. En una revisión de 35 casos en que se hizo TAC, 20 resultaron normales ${ }^{11}$. En nuestra serie los tres casos tuvieron TAC de encéfalo normal. Las imágenes originadas por Listeria pueden ser tan características en la romboencefalitis por este origen que su apariencia puede ser suficientemente diagnóstica. Se ha enfatizado en la importancia de encontrar lesiones unilaterales con un aspecto bien definido en las imágenes por RNM. En nuestros tres casos las lesiones tenían una apariencia similar, el fenómeno inflamatorio adoptaba la forma de una clavija con la porción ancha superior (puente) y su porción delgada hacia abajo (bulbo). Esta apariencia es semejante con la del caso recientemente publicado en España ${ }^{6}$. Siempre el diagnóstico diferencial debe hacerse con tuberculosis, enfermedades micóticas (criptococcus y aspergi-

\section{REFERENCIAS}

1. Stone S, ShoENBerger J. Update on emerging infections: news from the centers for disease control and prevention. Ann Emer Med 2001; 38(3): 340-1.

2. MANDelL G. Principles and practice of infectious disease. V edition, 2000; LORVER B (cap 195) 2009-11. llus) y cuadros entre los cuales figura el virus del herpes simple u otros virus oportunistas. Finalmente, llama la atención la semejanza de estas lesiones tan inhabituales en el tronco cerebral, sugiriendo algún factor local que pueda dar cuenta de esta susceptibilidad especial de una sola mitad del romboencéfalo.

El líquido cefalorraquídeo que se asociaba a este síndrome neurológico también es de interés diagnóstico. Así, en el caso 1 el LCR reveló 820 elementos por $\mathrm{mm}^{3}$, en el caso 2, 570 elementos y en el caso 3, 145 polinucleares por $\mathrm{mm}^{3}$. Estas cifras coinciden con la media observada en el conjunto de casos publicados ${ }^{11}$. La tinción de Gram fue positiva en nuestro Caso 1; aunque habitualmente es negativa como sucedió en los casos 2 y 3 . En lo que se refiere a cultivos, el de LCR es solamente positivo en 33\%, y en la sangre en $61 \%$, en muestras repetidas ${ }^{12}$. El diagnóstico también puede formularse por pruebas serológicas e inclusive por anticuerpos monoclonales, pero la alta frecuencia de las infecciones por Listeria hacen menos significativo este hallazgo ${ }^{13}$. Un líquido claro con proteínas y glucosa normales, en presencia de PMN, debe llamar la atención, especialmente en un paciente con síntomas del romboencéfalo. En la literatura se ha hecho hincapié en esta expresión «contradictoria»del LCR en la listeriosis que afecta el puente y bulbo raquídeo ${ }^{7}$.

Los resultados de los estudios microbiológicos en ocasiones son lentos o no concluyentes. Por consiguiente la validación de la hipótesis clínica en este cuadro es fundamental para el inicio precoz de un tratamiento antibiótico. Un síndrome romboencefálico en un paciente adulto debe incluir en el estudio pruebas que descarten la presencia de Listeria monocytogenes.

3. McLauchun J. Human listeriosis in Britain, 19671985, a summary of 722 cases. 1. Listeriosis during pregnancy and in the newborn. Epidemiol Infect 1990; 104: 181-90.

4. McLauchun J. Human listeriosis in Britain, 19671985, a summary of 722 cases. 2. Listeriosis in non pregnant individuals, a changing pattern of infection and seasonal incidence. Epidemiol Infect 1990; 104: 191-201. 
5. Mylonakis E, Hohmann E, Calderwood S. Listeria monocytogenes: 33 Years' Experience at a General Hospital and Review of 776 Episodes from the Literature. Medicine 1998; 77: 333-6.

6. Ortín-Castaño a, Moreiro MT, Ines S, De la Caue B, Rodríguez-Encinas A. Romboencefalitis por Listeria monocytogenes. Probable utilidad de la dexametasona asociada al tratamiento antibiótico. Rev Neurol 2002; 34: 830-2.

7. Frith RW, Buchanan PR, Glasgow GL Listeria monocytogenes infection with rhomboencephalitis. J Neurol Neurosurg Psychiatry 1987; 50: 1383-4.

8. Nielman RE, LORBer B. Listeriosis in adults: a changing pattern. Report of eight cases and review of the literature, 1968-1978. Rev Infect Dis 1980; 2: 207-27.
9. BICKERSTAFF ER. Brainstem encephalitis: further observations on a grave syndrome with benign prognosis. BMJ 1957; 1: 1384-7.

10. EсK H. Encephalomyelitis listeriacea apostematosa. Schweitz Med Wochenschr 1957; 87: 210-4.

11. Peeters A, Waer M, Michielsen P, Verbist L, Carton $\mathrm{H}$. Listeria monocytogenes meningitis in adults: sixteen consecutive cases, 1973-1982. Scand J Infect Dis 1987; 19: 55-60.

12. Uldri PA, Kuntzer T, Bogoussiavsky J, Regli F, Mikцossy J, Biшe J et al. Early symptoms and outcome of Listeria monocytogenes rhomboencefalitis: 14 adult cases. J Neurol 1993; 240: 235-42.

13. Amstrong RW, Fung PC. Brainstem encephalitis (rhomboencephalitis) due to Listeria monocytogenes: case report and review. Clin Infect Dis 1993; 16: 689-702. 